\title{
sciendo
}

\section{Intra and Interzone Differences of Attack and Counterattack Efficiency in Elite Male Volleyball}

\author{
by \\ Zoran Grgantov'1, Igor Jelaska1, Dragutin Šuker ${ }^{2}$
}

\begin{abstract}
The primary goal of this study was to identify and explain differences in a volleyball set between winning and defeated teams, based on frequency and efficiency of the attack and counterattack, both overall and from particular zones of the volleyball court. Research was conducted on a randomly chosen sample of 206 sets played in 55 matches of the Men's Champions League. A total of 10555 spikes in the attack and counterattack from various zones of the volleyball court were analyzed. Between-subjects $2 \times 5$ factorial ANOVA (Outcome $\times Z o n e)$ was used to identify significant differences between the set outcome and zones or their interaction for both attack and counterattack efficiency. Significant differences were found in the efficiency of spikes in attacks and counterattacks from various zones of the volleyball court and between winning and losing teams. Post-hoc analysis of interaction effects also revealed significant differences. The obtained results substantiate the importance of spiking, both in the attack and counterattack, for winning a volleyball set, and indicate the specific values of spiking in the attack and counterattack from various zones, for both winning and defeated teams. The results of this study can be useful for coaches, in evaluation of player's performance in the match, in planning and programming the training process as well as in the technical and tactical preparation of the team for the tournament.
\end{abstract}

Key words: notational analysis, spiking, performance quality, factorial ANOVA.

\section{Introduction}

Volleyball is an intermittent sport comprised of seven basic game phases (serve, pass, set, spike, attack coverage, block and field defense). These phases connect into a variety of complexes. Some authors employ a more detailed breakdown into six complexes (Hileno and Busca, 2012), but the most frequent one is the division into complex 1 (attack) and complex 2 (counterattack) (Costa et al., 2012; Rodriguez-Ruiz et al., 2011). The game phases set, spike and attack coverage repeat themselves in somewhat different circumstances both in the attack (following the pass) and in the counterattack (following field defense).

Numerous authors have established that spikes in the attack and counterattack contribute most to the explanation of tournament success
(Cox 1974; Eom and Schutz, 1992; Grgantov et al., 2005; Inkinen et al., 2013).

In studies carried out so far, the performance quality of spikes in the attack and counterattack was brought into connection, for instance, with the performance quality of the other game phases (Mesquita et al., 2007; Palao et al., 2005, 2006; Rocha and Barbanti, 2004), with player rotation in the field (Yin and Dong, 2007; Zadražnik et al., 2009), with a part of the set (Marcelino et al., 2012), with specific characteristics of individual player roles (Bergeles and Nikolaidou, 2011; Marcelino et al., 2014; Matias and Greco, 2011; Mesquita et al., 2007) and with the outcome of the set or, respectively, the match (Claver et al., 2013; Klaričić et al., 2018).

However, information is lacking on the

1 - Faculty of Kinesiology, University of Split, Split, Croatia.

2 - Faculty of Applied Sciences, University of Rijeka, Rijeka, Croatia. 
variances in spiking frequency and efficiency from particular zones of the volleyball court. By systematic data gathering, spike performance in the attack and counterattack can be brought into relation with the position of the performance. Front row players can spike from the right front position, from the middle front position and from the left front position (zones 2, 3 and 4, respectively); they are accompanied by two players from the back row who jump and spike behind the attack line, from the middle back position (zone 6) or from the right back position (zone 1). In modern volleyball, attacks from zone 5 are very rare. There are two main reasons for that fact. First, during defence there is a libero in that zone who is not allowed to spike. Second, during the attack and counterattack from zone 4 , spikes are mostly realized by outside hitters, so it is not tactically appropriate to duplicate the attacks from zones 4 and 5 .

Following the above considerations, the primary objective of this study was to analyze main and interaction effects of the outcome (Winner vs. Defeated) and spiking zone (4, 3, 2, 1, $\& 6)$ on attack and counterattack efficiency.

\section{Methods}

\section{Participants}

Research was conducted on a randomly chosen sample of 206 sets played in 55 matches of the Men's Champions League from 2008 to 2012. A total of 10555 spikes in the attack and counterattack from various zones of the volleyball court were analyzed.

\section{Measures}

For each individual set, for the winning and the defeated team in the set, based on a 4-level Likert scale, the efficiency of each individual spike in Complex 1 and Complex 2 was rated, taking the volleyball field zone into account $(4,3,2,1$, \& 6). For the spikes that took place between the two zones, the attack zone was defined based on the type of the attack and the playing role of the attacker. For the attack and counterattack, the following criteria of performance quality estimation were applied (Matias and Greco, 2011):

Rating 4 was assigned to a spike resulting in an immediate point scored. This referred to balls that hit the opponent's court or that resulted in a performance error by the opposing team in block or field defense.
Rating 3 was assigned to all spike performances after which the spiking team had a dominant position in the further course of the rally. This referred to situations when, after the spike, the ball deflected on the block and returned to the attacking team's court, but in such a way that the setter was able to launch a repeat attack with a higher number of options, or when the opposing team gained possession of the spiked ball, but was unable to launch a good counterattack (the field defense player played the ball inaccurately, therefore setting and spiking in the counterattack were performed under difficult conditions, leaving the setter with a very limited number of options).

Rating 2 was assigned when the spiked ball deflected on the block and returned to the attacking team's court, but in such a way that performance of a repeat attack was made very difficult. Another possibility was that, after the spike, the opposing team managed to play the ball in field defense in a way that enabled them to launch a successful counterattack.

Rating 1 was assigned if a performance error was made in spiking (the ball went into the net or landed out of bounds, the ball deflected on the block and stroke the floor in the attacking team's court, or the spiker committed a violation of the game's rules).

After raw data had been collected, efficiency coefficients $(E I)$ within one set were calculated for winners and defeated teams, in the attack and counterattack separately, for every zone, by application of the following formula:

$$
E I=\frac{1 \cdot n_{1}+2 \cdot n_{2}+3 \cdot n_{3}+4 \cdot n_{4}}{n_{1}+n_{2}+n_{3}+n_{4}},
$$

where $\mathrm{n}_{1}, \mathrm{n}_{2}, \mathrm{n}_{3}, \mathrm{n}_{4}$ are the numbers of Rating 1 , Rating 2, Rating 3, and Rating 4, respectively. It is obvious that raw data were transformed on an interval scale suitable for further parametric statistical analysis.

Efficiency coefficients were applied as, in research conducted up to now (Marcelino et al., 2008), they were found to be better predictors of team performance as compared to the individual variables based on which they were calculated.

Considering the fact that, in modern volleyball, attacks are very rarely or never launched from zone 5 in the course of the match, it should be noted that attacks from that zone were not taken into account in the analyses. 


\section{Procedures}

The data were collected by means of specialized computer software, Data Volley Professional 3.2.1. (Data Project, Salerno, Italy), from video recordings made by a camera that was placed in such a position to clearly cover the entire court and all players in the court.

\section{Statistical Analysis}

Reliability analysis was conducted on a subsample of 11 randomly chosen sets (which provided 22 entities). Single rater reliability was obtained by application of the test-retest method. The third author of this research, expert coach with over three decades of training experience, conducted the test and retest, and the second measurement was performed 4 weeks after the first measurement. Additionally, reliability was assessed by another expert rater (a professional statistician of the Slovenia's Bled Team that competed in the Men's Volleyball Champions League) on the same subsample; furthermore, the interrater reliability coefficient ICC (2.2) was calculated. Reliability of volleyball field zone assessment $(4,3,2,1, \& 6)$ by raters was estimated using Cohen's Kappa ( $\kappa)$.

Thus, reliability assessment was not conducted on mean values obtained on a larger number of individual events, as, in this case, the same mean values can be obtained from various raters or from the same rater in repeated measurements (high level of reliability), although they have assigned different ratings to the individual events. In order to avoid such a possibility, reliability analysis was performed on individual events. Calculations produced two indicators that analyzed correlation of individual events in two assessment points (Kendall's Tau Correlation Coefficient and Spearman's Rank Correlation Coefficient).

Calculation of descriptive statistical indicators of distribution of the variable spike in the attack and counterattack by winning and defeated teams from volleyball zones $(4,3,2,1$, \& 6) included calculation of the arithmetic mean (AM) and standard deviation. Using simple comparison between proportions, differences in proportions between winning and defeated teams in spike frequencies in the attack and counterattack from observed zones were estimated.

Factorial $2 \times 5$ between-subjects ANOVA was used to assess the main and interaction effects of the Outcome (Winner vs. Defeated) and Zone $(4,3,2,1, \& 6)$ on attack and counterattack efficiency. Partial eta-squared $\left(\eta^{2}\right)$ was used for the effect size assessment. Additionally, the post hoc Bonferroni correction was applied. All data were processed using the Statistica 12.0 (StatSoft, Tulsa, OK, USA) software package. Type I error was set at $\alpha=0.05$.

\section{Results}

Reliability analysis was conducted on a randomly chosen subsample of 11 sets (i.e. 503 spikes) in the attack and counterattack, which constituted $4.78 \%$ of the whole sample. Due to the nonparametric nature of the raw data, the Spearman coefficient rank correlation was used ( $\mathrm{R}$ $=.999 ; p<.001)$, as well as the Kendall $\tau$ coefficient $(\tau=.997 ; p<.001)$ between test and retest measurement of the rater, and very high reliability was assessed. Additionally, the interrater reliability coefficient between two raters was calculated on the same sample, and a high level of reliability was obtained $(\operatorname{ICC}(2.2)=.971)$ as well. For interrater reliability estimation of zone assessment, high reliability was also identified (Cohen's Kappa, $\kappa=.982$ ).

As a basic descriptive insight into frequencies, Table 1 shows differences between winning and defeated teams in spike frequencies in the attack and counterattack from observed zones.

Table 1 disclosed no significant differences between proportions through zones, both for winners and defeated teams, for the attack and counterattack, but a tendency towards significance in zone $3(p=.064)$ and zone $4(p=$ $.074)$ for the attack and in zone $4(p=.091)$ for the counterattack is visible.

Regarding efficiency coefficients, a significant main effect of the Zone factor was identified $\left(\mathrm{F}_{4,1816}=4.997 ; p<.001 ; \eta^{2}=.011\right)$ for the attack. Applying the Bonferroni correction, significant differences were found between zone 3 and zone $2(p=.049)$ as well as zone 3 and zone 4 $(p<.001)$. Also for the counterattack, a significant main effect of the Zone factor was identified $\left(\mathrm{F}_{4,1465}\right.$ $\left.=5.897 ; p<.001 ; \eta^{2}=.016\right)$. With the Bonferroni correction, significant differences were observed between zone 3 and zone $1(p<.001)$, zone 3 and zone $2(p=.001)$, zone 3 and zone $4(p<.001)$. 
Differences between zone 3 and zone 6 were almost significant $(p=0.051)$. A significant main effect of the set Outcome factor was identified for the attack $\left(\mathrm{F}_{1,1816}=92.350 ; p<.001 ; \eta^{2}=.048\right)$ and also for the counterattack $\left(\mathrm{F}_{1,1465}=43,519 ; p<.001\right.$; $\left.\eta^{2}=.029\right)$.
The interaction effect Outcome $\times$ Zone was not found to be significant for the attack $\left(\mathrm{F}_{4,1816}=\right.$ $\left.1.281 ; p=.275 ; \eta^{2}=.003\right)$ neither for the counterattack $\left(\mathrm{F}_{4,1465}=0.295 ; p=.881 ; \eta^{2}=.001\right)$, yet by application of the post hoc Bonferroni correction, some significant differences were observed in both cases (Table 2).

Table 1

Differences between winning and defeated teams in spike frequencies in the attack

\begin{tabular}{|c|c|c|c|c|c|c|c|}
\hline \multirow[b]{2}{*}{ Zone } & \multicolumn{2}{|c|}{ Total } & \multicolumn{2}{|c|}{$\begin{array}{c}\text { Attack } \\
\text { winners }\end{array}$} & \multicolumn{2}{|c|}{$\begin{array}{c}\text { Attack } \\
\text { defeated }\end{array}$} & \multirow[t]{2}{*}{$p$} \\
\hline & $\mathbf{N}$ & $\%$ & $\mathbf{N}$ & $\%$ & $\mathbf{N}$ & $\%$ & \\
\hline 1 & 970 & 14.76 & 446 & 14.87 & 524 & 14.67 & .460 \\
\hline 2 & 1144 & 17.41 & 511 & 17.04 & 633 & 17.72 & .381 \\
\hline 3 & 1632 & 24.84 & 798 & 26.61 & 834 & 23.35 & .064 \\
\hline 4 & 2422 & 36.86 & 1059 & 35.31 & 1363 & 38.16 & .074 \\
\hline 6 & 403 & 6.13 & 185 & 6.17 & 218 & 6.10 & .488 \\
\hline \multirow[t]{2}{*}{ Total } & 6571 & 100 & 2999 & 100 & 3572 & 100 & \\
\hline & \multicolumn{2}{|c|}{ Total } & \multicolumn{2}{|c|}{$\begin{array}{c}\text { Counterattack } \\
\text { winners }\end{array}$} & \multicolumn{2}{|c|}{$\begin{array}{c}\text { Counterattack } \\
\text { defeated }\end{array}$} & $p$ \\
\hline Zone & $\mathbf{N}$ & $\%$ & $\mathbf{N}$ & $\%$ & $\mathbf{N}$ & $\%$ & \\
\hline 1 & 661 & 16.59 & 337 & 16.35 & 324 & 16.85 & .431 \\
\hline 2 & 863 & 21.66 & 451 & 21.87 & 412 & 21.43 & .437 \\
\hline 3 & 419 & 10.52 & 233 & 11.31 & 186 & 9.67 & .293 \\
\hline 4 & 1769 & 44.40 & 884 & 42.88 & 885 & 46.02 & .091 \\
\hline 6 & 272 & 6.83 & 156 & 7.59 & 116 & 6.03 & .308 \\
\hline Total & 3984 & 100 & 2061 & 100 & 1923 & 100 & \\
\hline
\end{tabular}

Legend: $N$ - number of spikes during the attack from particular zones,

$\%$-percentage of total spikes, $p$ - significance while testing proportions between winning and defeated teams

Table 2

Attack and counterattack efficiency of winning and defeated teams between observed zones.

Data are presented as mean \pm standard deviation.

\begin{tabular}{clccccc}
\hline & \multicolumn{1}{c}{ Zone } & $\mathbf{1}$ & $\mathbf{2}$ & $\mathbf{3}$ & $\mathbf{4}$ & $\mathbf{6}$ \\
\hline \multirow{2}{*}{$\begin{array}{c}\text { Winners } \\
\text { (W) }\end{array}$} & Attack (A) & $\begin{array}{c}3.12 \pm \\
.78\end{array}$ & $3.10 \pm .79$ & $3.29 \pm .59$ & $3.00 \pm .52^{\mathrm{y}}$ & $3.23 \pm .94$ \\
\cline { 2 - 7 } & Counterattack(C) & $\begin{array}{c}2.86 \pm \\
.95\end{array}$ & $2.89 \pm .88$ & $3.15 \pm .99$ & $2.85 \pm .70$ & $2.91 \pm 1.11$ \\
\hline \multirow{2}{*}{$\begin{array}{c}\text { Defeated } \\
\text { (D) }\end{array}$} & Attack (A) & $\begin{array}{c}2.81 \pm \\
.92^{\mathrm{a}}\end{array}$ & $\begin{array}{c}2.81 \pm \\
.78^{\mathrm{a}}\end{array}$ & $2.92 \pm .71^{\mathrm{a}}$ & $2.74 \pm .49^{\mathrm{a}}$ & $2.72 \pm 1.08^{\mathrm{a}}$ \\
\cline { 2 - 7 } & Counterattack(C) & $\begin{array}{c}2.46 \pm \\
.98^{\mathrm{b}}\end{array}$ & $\begin{array}{c}2.52 \pm \\
.89^{\mathrm{b}}\end{array}$ & $\begin{array}{c}2.89 \pm \\
1.09^{\mathrm{x}}\end{array}$ & $2.56 \pm .67$ & $2.60 \pm 1.10$ \\
\hline
\end{tabular}

a-Significant differences in the same zone (column) compared to $W-A$,

${ }^{b}$-Significant differences in the same zone (column) compared to $W-C$,

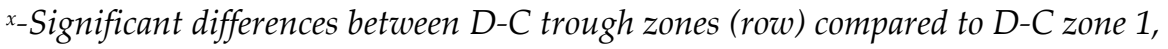

y-Significant differences between $W$-A trough zones (row) compared to $W$ - $A$ zone 3. 


\section{Discussion}

As a result of analysis of differences between winning and defeated teams in the frequency of spiking from particular zones (Table 1 ), it was found that setters from the winning and defeated teams showed no significant differences in terms of ball distribution to particular zones, either in the attack or in counterattack. However, it can be noted in both the attack and counterattack that winning teams were spiking somewhat more frequently from zone 3, and less frequently from zone 4. Although these differences are not statistically significant (they are borderline significant), a spiking frequency from zone 3, which is higher by a few percentage points in the tournament, may represent a difference that can produce a small, but sometimes decisive advantage towards winning the volleyball set. As a matter of fact, this study confirmed that attacks with fast balls from the middle front position, from zone 3 , were the most efficient ones (Table 2), which is in line with the results of studies conducted by Ramos et al. (2004) and Paschali et al. (2004). Such attacks are only possible after precise passes or, respectively, after precise defenses of opposing player's spikes, when the ball goes precisely into the setting zone. Teams whose setters distribute balls more evenly to all zones are, in principle, more successful than teams predominantly playing from the sides of the net, particularly from zone 4 (Araujo et al., 2010; Ramos et al., 2004). In this study as well, the least spiking efficiency was found in attacks from zone 4 . In this zone, the spikers are most often receivers-attackers who must concentrate both on receiving the serve and on attacking, which certainly has an impact on spiking efficiency. Besides, opponent servers very often use a tactic where they make short and deep serves to the receiver positioned in the front row. This way, they intend to make it difficult for the receiver to switch from pass to attack. Very often, setters set balls into that zone in difficult situations, when they cannot launch attacks by fast balls from the middle front position (zone 3). Araujo et al. (2010) found that more than $40 \%$ of all set balls were directed to zone 4 , and that in the majority of these actions, the receivers-attackers from zone 4 had to confront a double or even triple block. One should keep in mind that players in the receiverattacker position are, on average, of a slightly shorter stature in comparison to middle hitters and opposite hitters (Sattler et al., 2012), which can also have a negative impact on spiking efficiency. Therefore, we can assume that, in defeated teams, the frequency of balls played in the attack to zone 4, which is higher by a few percentage points, and the frequency of balls played to zone 3, which is lower by a few percentage points, may be one of the reasons for their failure to win the set.

Comparison of average efficiency coefficient values (Table 2) clearly shows that both winning and defeated teams are more efficient in the attack, from all zones, as compared to the counterattack. Higher efficiency in the attack as compared to the counterattack has been found in elite female volleyball as well (Marelić et al., 2004).

This was expected, considering the difficult spatial and temporal conditions in the performance of counterattacks in comparison to attacks (Marcelino et al., 2011). A spike in the counterattack is much more challenging than a spike in the attack, as the transition from a block or field defense to the attack is much more complex than the transition from the pass to the attack. That is why in the counterattack balls are directed to setters and, as a result, balls directed by the setters to the hitters are less precise and slower than the ones in the attack, which has an impact on the spiking quality (Marcelino et al., 2014). Furthermore, in a sizeable number of cases, after the block, the middle hitter has no time to approach and jump for the spike, which makes the job much easier for the opposing blockers. Therefore, in this study, elite male volleyball teams have a higher percentage of setting into zone 4 in the counterattack (44\%) as compared to the attack (36\%).

This leads to the conclusion that the smaller number of players ready to spike in the counterattack will reduce the space to be covered by opposing blockers, while the higher and longer flight of the ball will give them more time to prepare the block. That is why hitters in the counterattack are often confronted by a double or triple block.

Analysis of interzone differences in efficiency coefficients allows for the conclusion that the observed teams were significantly more successful in the attack and counterattack from 
the middle of the net out of zone 3 than from the sides of the net - zones 4 and 2 in the attack and zones 4, 2 and 1 in the counterattack (Table 2).

In the attack, winning teams were successful from all zones, as the average rating was above 3 in each zone (Table 2). Their attacks were most successful if performed from the middle positions (from zones 3 and 6). The first reason is that attacks from the middle positions are most often used after good passes. In such situations, opposing blockers have to deal with the threat of fast attacks by four hitters, two of them positioned at the sides of the net (zone 4 and zone 1 or 2) and another two from the middle position (zones 3 and 6). In such actions performed from zone 3 or zone 6 , the transition from set to spike will happen in the shortest time, which will make blocking difficult, particularly in the today's prevailing "read and react" blocking system. What's more, in well-performed attacks from the middle position, middle blockers will find it very difficult to discern during the initial part of the ball's trajectory whether the ball is going to be spiked by the middle hitter from zone 3 or by the receiver-attacker from the middle back position, zone 6 . That is why the majority of attacks from the middle position are performed against a single block or against a non-compact double or triple block. Therefore, it is obvious that the joint threat coming from four attackers along the full length of the net and at various distances from the net will make it considerably more difficult for opposing players to perform blocks and field defense actions, which is probably the main reason for the high spiking efficiency of winning teams from the middle position (Araujo et al., 2010).

In contrast to the winning teams, defeated teams have no attack efficiency coefficient above 3 from any of the zones. In comparison to winning teams, they are considerably less efficient from all zones, particularly from zones 6 and 3. Based on the results of previous studies, it may be assumed that the reasons lie not only in the players' attacking capabilities, particularly of attackers from zones 3 and 6. Precision of preceding game actions (serve reception and setting), the setter's predictability as well as the quality of opposing players in blocking actions can also have an impact on attack efficacy and consequently on the win or loss of the set (Afonso and Mesquita, 2011;
Bergeles and Nikolaidou, 2011; Marcelino et al., 2014; Silva et al., 2014).

In the counterattack, winning teams managed to maintain a high level of spiking efficiency that was even higher than the opposing team's spiking efficiency in the attack.

In the counterattack of defeated teams, significant differences were noted with regard to spiking efficiency from various zones. In comparison to the attack, such differences were expressed more strongly, as spiking efficiency in zone 3 was slightly lower, while in all other zones, a more substantial drop in spiking efficiency was noted. This drop was most strongly pronounced in zones 1 and 2, from where spikes were performed by opposite hitters in the majority of cases. It is known that opposite hitters have the very important task to perform spikes in difficult situations, after imprecise serve receptions and field defense actions, at which they have to confront a compact double or triple block (Araujo et al., 2010). Marcelino et al. (2014) also found that, by analysis of the zone from where the ball was set, it could be anticipated which player would spike the ball. For instance, middle hitters will perform an attack much more often when the ball was passed in an ideal manner, while opposite hitters will attack when the pass occurred outside the ideal setting zone. Therefore, it can be assumed that for a win in the set, it is important that opposite attackers have good spiking efficiency in difficult situations (that occur more often in the counterattack). Although significantly less points are scored by spiking in the counterattack than by spiking in the attack (Castro et al., 2011), scoring a point by a counterattack, from difficult situations, very often has an extremely motivating effect on the team that scored the point, while being demotivating for the opposing team. In other words, scoring such points can essentially determine the course of the remaining part of the set and therefore has a positive impact on the efficiency of all phases of the volleyball game.

\section{Conclusion}

The scientific contribution of this paper lies in the analysis of differences between winning and defeated teams with regard to efficiency of the attack and counterattack from particular zones of the volleyball court. The paper reaffirms the 
importance of spiking in the attack and counterattack in identification of differences between winning and defeated teams in the volleyball set. In order to win the set, in the attack, setters must evenly distribute the balls to various zones; in doing so, great importance is attached to spiking efficiency from all zones, and particularly high demands are put on efficient spiking from the middle position, by combined attacks from zones 3 and 6 . Due to difficult conditions of the game action, in counterattacks, spikes from the middle position occur much less often, but much more often from the sides of the net. The largest number of attacks is performed from zone 4 , but winning teams differ from defeated ones in that they have higher efficiency in spiking from zones 1 and 2 . This indirectly highlights the importance of the role of the opposite hitter who must maintain a high efficiency level in the most demanding situations, confronting the opponent's compact double or triple block.
The results of this study may be applied in order to optimize the training process in elite male volleyball aimed at increasing efficiency of spikes from particular zones, in the attack and counterattack. Coaches of elite teams may use the gained results in order to encourage setters to distribute balls to hitters in a more efficient way, taking into account the specific capabilities of individual players (i.e. body height of the players, height of the jumps, etc.), but also the specific characteristics of spikes from various zones, in the attack and counterattack.

In future studies, the frequency and efficiency of the attack and counterattack from particular zones need to be analyzed according to the quality of the preceding game actions (serve reception, field defense and setting) and of the opposing team's block.

\section{References}

Afonso J, Mesquita I. Determinants of block cohesiveness and attack efficacy in high-level women's volleyball. Eur J Sport Sci, 2011; 11(1): 69-75

Araújo RM, Castro J, Marcelino R, Mesquita, IR. Relationship between the Opponent Block and the Hitter in Elite Male Volleyball. J Quant Anal Sports, 2010; 6(4): 1-12

Bergeles N, Nikolaidou M. Setter's performance and attack tempo as determinants of attack efficacy in Olympic-level male volleyball teams. Int J Perform Anal Sport, 2011; 11(3): 535-544

Castro J, Souza A, Mesquita I. Attack efficacy in volleyball: Elite male teams. Percept Motor Skill, 2011; 113(2): $395-408$

Claver F, Jiménez R, Gil A, Moreno A, Moreno MP. Relationship between performance in game actions and the match result. A study in volleyball training stages. Journal of Human Sport E Exercise, 2013; 8(3): 651-659

Costa GCT, Afonso J, Brant E, Mesquita I. Differences in game patterns between male and female youth volleyball. Kinesiology, 2012; 44(1): 60-66

Cox RH. Relationship between Selected Volleyball Skill Components and team performance of men's northwest "AA" volleyball teams. Res Q Exercise Sport, 1974; 45(4): 441-446

Eom HJ. Schutz RW. Statistical analyses of volleyball team performance. Res Q Exercise Sport, 1992; 63(1): 1118

Grgantov Z, Katić R, Marelić N. Effect of new rules on the correlation between situation parameters and performance in beach volleyball. Coll Antropol, 2005; 29(2): 717-722

Hileno R, Buscà B. Observational tool for analyzing attack coverage in volleyball. Rev Int Med Cienc Act Fís Deporte, 2012; 12(47): 557-570

Inkinen V, Häyrinen M, Linnamo V. Technical and tactical analysis of women's volleyball. Biomed Hum Kinetics, 2013; 5(1): 43-50

Klaričić I, Grgantov Z, Jelaska I. Prediction Of Efficiency In Elite Volleyball: Multiple Regression Approach. 
Acta Kinesiologica, 2018; 12(1): 79-85

Marcelino R, Mesquita I, Afonso J. The weight of terminal actions in volleyball. Contributions of the spike, serve and block for the teams' rankings in the World League 2005. Int J Perform Anal Sport, 2008; 8(2): $1-7$

Marcelino R, Mesquita I, Sampaio J. Effects of quality of opposition and match status on technical and tactical performances in elite volleyball. J Sports Sci, 2011; 29(7): 733-741

Marcelino RO, Sampaio JE, Mesquita IM. Attack and serve performances according to the match period and quality of opposition in elite volleyball matches. J Strength Con Res, 2012; 26(12): 3385-3391

Marcelino R, Afonso J, Mesquita I, Moraes JC. Determinants of attack players in high-level men's volleyball. Kinesiology, 2014; 46(2): 234-241

Marelić N, Rešetar T, Janković V. Discriminant analysis of the sets won and the sets lost by one team in A1 Italian volleyball league-A case study. Kinesiology, 2004; 36(1): 75-82

Matias CJ, Greco PJ. Offensive organization assessment of winners of brazilian Volleyball Superleague setters. Revista Brasileira de Ciências do Esporte, 2011; 33(4): 1007-1028

Mesquita I, Manso FD, Palao JM. Defensive participation and efficacy of the libero in volleyball. J Hum Mov Stud, 2007; 52(2): 95-107

Palao JM, Santos JA, Ureña A. The effect of the setter's position on the spike in volleyball. J Hum Mov Stud, 2005; 48(1): 25-40

Palao JM, Santos, JA, Ureña A. Effect of reception and dig efficacy on spike performance and manner of execution in volleyball. J Hum Mov Stud, 2006; 51(4): 221-238

Paschali E, Papadimitriou A, Zetou E, Gourgoulis V. The effect of set on the structure of the opponents' block in the 1st National Division. Inquiries in Sport \& Physical Education, 2004; 2(1): 18-25

Ramos MHKP, Nascimento JV, Donega AL, Novaes AJ, Souza RR, Silva TJ, Lopes AS. Setting action's internal structure on Brazilian male volleyball national championship teams 2002/2003. Revista Brasileira de Ciência e Movimento, 2004; 12(4): 33-37

Rocha CM, Barbanti VJ. An analysis of the confrontations in the first sequence of game actions in Brazilian volleyball. J Hum Mov Stud, 2006; 50(4): 259-272

Rodriguez-Ruiz D, Quiroga ME, Miralles JA, Sarmiento S, de Saá Y, García-Manso JM. Study of the Technical and Tactical Variables Determining Set Win or Loss in Top-Level European Men's Volleyball. J Quant Anal Sports, 2011; 7(1): 1-15

Silva M, Lacerda D, João PV. Game-Related Volleyball Skills that Influence Victory. J Hum Kinet, 2014; 41(1): 173-179

Stanganelli LCR, Dourado AC, Oncken P, Mançan S, Da Costa SC. Adaptations on Jump Capacity in Brazilian Volleyball Players Prior to the Under-19 World Championship. J Strength Con Res, 2008; 22(3): 741-749

Zadražnik M, Marelić N, Rešetar T. Differences in rotations between the winning and losing teams at the youth European volleyball championships for girls. Acta Univ Palacki Olomuc, Gymn, 2009; 39(4): 33-40

Yin ZY, Dong TS. Analysis on First Attacks of Chinese Women Volleyball Team. China Sport Science and Technology, 2007; 3(1): 21-26

\section{Corresponding author:}

\section{Igor Jelaska}

Associate Professor

Faculty of Kinesiology, University of Split, 06 Tesla's Street, 21000 Split, Croatia

Phone: +385 (0) 21302 440; E-mail: jelaska@kifst.hr 